\title{
PREVALENCE OF INTRAORBITAL NEOPLASMS- A RETROSPECTIVE STUDY FOR SEVEN YEARS
}

Seena A. $R^{1}$, Sreedevi A. $R^{2}$

${ }_{1}^{1}$ Associate Professor, Department of Pathology, Government Medical College, Thiruvananthapuram, Kerala.

${ }^{2}$ Associate Professor, Department of Pathology, Government Medical College, Thiruvananthapuram, Kerala.

\section{BACKGROUND}

ABSTRACT

A large variety of tumours are seen to arise from the orbit. These can be malignant, benign or intraepithelial neoplasms. Studies were conducted on these tumours and their prevalence in different parts of the world. The prevalence of the individual tumours in different regions of world are different. Metastatic tumours are the most common in a study, while basal cell carcinoma tops the chart in another. Rhabdomyosarcoma is common in some studies, while lymphoma is one of the commonest in some places. This study was conducted to learn the pattern in Kerala and compare it with the patterns in other regions.

\section{MATERIALS AND METHODS}

The descriptive study was conducted in the Regional Institute of Ophthalmology, Thiruvananthapuram. All tumours involving the orbits that were seen in the centre from 2010 September to August 2017 were included.

\section{RESULTS}

Benign tumours constitute the majority among which nevi, angiomas and squamous papilloma are the commonest. The prevalence of benign and malignant tumours is different from studies conducted in some other centres. For example, metastatic tumours and basal cell carcinoma are the commonest among the malignant tumours in the studies from some centres, while squamous cell carcinoma and lymphoma were the commonest in our study. However, similar patterns of prevalence were seen in studies conducted in centres closer to our centre.

\section{CONCLUSION}

Distribution pattern of orbital tumours in Kerala are comparable to that in some other Indian states and neighbouring countries like Pakistan. This may be due to factors like viral infections like Human Papilloma Virus, terrestrial radiation, genetic factors etc.

\section{KEY WORDS}

Intraorbital Tumours, Meibomian Carcinoma, Ocular Lymphomas, Metastatic Tumours.

HOW TO CITE THIS ARTICLE: Seena AR, Sreedevi AR. Prevalence of intraorbital neoplasms- a retrospective study for seven years. J. Evolution Med. Dent. Sci. 2018;7(20):2449-2452, DOI: 10.14260/jemds/2018/551

\section{BACKGROUND}

The orbit, though a small portion of the face, is the seat of a wide variety of neoplasms. This include both benign and malignant, both primary and secondary. The large variety of tumours can be credited to the different types of tissues in the orbit. Thus, the eyeball gives rise to tumours arising from retina, choroid and conjunctiva namely Retinoblastoma, Melanoma, Squamous carcinoma etc.

Extraocular tissues like muscles, both skeletal and smooth muscles, nerves and blood vessels also give rise to tumours like leiomyosarcoma, rhabdomyosarcoma, neurofibroma, schwannoma and angioma, both benign and malignant. Eyelids are another main site of primary tumours giving rise to epithelial tumours like papilloma, seborrhoeic keratosis, pigmented tumours like nevus, in addition to the malignant tumours like melanoma, basal cell carcinoma and squamous cell carcinoma. Besides, the lids consist of glands like Meibomian glands and Zeis glands which are modified

'Financial or Other Competing Interest': None.

Submission 09-03-2018, Peer Review 26-04-2018,

Acceptance 02-05-2018, Published 14-05-2018.

Corresponding Author:

Sreedevi $A$. $R$

Associate Professor,

Department of Pathology,

Government Medical College,

Thiruvananthapuram, Kerala.

E-mail: seenaar@yahoo.com

DOI: $10.14260 /$ jemds $/ 2018 / 551$ sebaceous glands. These and other minor glands along with lacrimal glands give rise to benign tumours like pleomorphic adenoma and malignant tumours like sebaceous carcinoma, adenoid cystic carcinoma etc.

The lymphoid tissue also can be the seat of neoplasm, namely lymphoma. Usually, orbital lymphomas are of nonHodgkin's type and are mostly of low grade.

The relative incidence and prevalence of orbital tumours has been studied by many centres all over the world. The percentage of individual tumours seems different in different regions. In a study conducted in Netherlands, $10.9 \%$ of orbital tumours were malignant, of which $67 \%$ were lymphomas followed by Rhabdomyosarcoma constituting $12 \% .{ }^{1}$

In a study conducted in China, on the other hand, the lacrimal gland tumours topped the prevalence charts accounting for $26 \%$ followed by rhabdomyosarcomas constituting $15 \%$. Lymphoma accounted for only $10 \% .^{2}$

Another study, which was conducted in Nepal showed Sebaceous carcinoma in the first position accounting for $8 \%$ of all the tumours. Basal cell carcinoma comes second, constituting $7 \%$ followed by melanoma $(3.5 \%)$ and squamous carcinoma $(1.7 \%){ }^{3}$

The study of orbital tumours conducted in Pakistan ${ }^{4}$ showed that Squamous cell carcinoma, Retinoblastoma and Lymphoma topped the charts with equal incidence, each accounting for $14 \%$ of the tumours. A similar study in Gujarat $^{5}$ showed Lymphoma at the top with $33 \%$, closely followed by Squamous cell carcinoma with $28 \%$, squamous 
carcinoma in situ 6\%, sebaceous carcinoma 20\%, retinoblastoma and melanoma $14 \%$ each and basal cell carcinoma $6 \%$.

It was definite from these study results that the tumours vary in prevalence in different parts of the world. The study was conducted in Kerala, one of the states in Southern India to know the pattern of distribution of tumours in this part of the world and to see whether it is comparable with any of the studies before.

\section{Objectives}

1. To study the prevalence in Kerala of various tumours occurring in the orbit and to compare the pattern of prevalence with that from different parts of the world.

2. To postulate reasons for the difference of patterns, if any.

\section{MATERIALS AND METHODS}

The descriptive study was conducted in the Regional Institute of Ophthalmology, Trivandrum, a tertiary care centre. All tumours that came to the centre during the period from August 2010 to July 2017 were included.

The prevalence of tumours were tabulated and the distribution pattern obtained. The pattern thus obtained was compared with similar studies conducted in different parts of the world. The differences were scrutinised and correlating with the epidemiology of the respective tumours, an attempt is made to find out the reason for the difference.

\section{RESULTS}

A total of 500 cases were studied. Among these, 392 were benign neoplasms and 108 were malignant cases.

\begin{tabular}{|c|c|c|}
\hline Tumour & Number & Percentage of Total \\
\hline Squamous papilloma & 66 & 13.2 \\
\hline Nevus & 136 & 27.2 \\
\hline Seborrhoeic keratosis & 50 & 10 \\
\hline Intraepithelial neoplasia & 30 & 0.6 \\
\hline Angioma & 52 & 10.4 \\
\hline Other epithelial tumours & 29 & 5.8 \\
\hline Soft tissue tumours & 23 & 4.6 \\
\hline \multicolumn{2}{|c|}{ Table 1. Benign Tumours of the Orbit } \\
\hline
\end{tabular}

Source: Primary Data.

\begin{tabular}{|c|c|c|c|}
\hline Tumour & Number & $\begin{array}{c}\text { Percentage } \\
\text { among Malignant } \\
\text { Tumours }\end{array}$ & $\begin{array}{c}\text { Percentage } \\
\text { among all } \\
\text { Tumours }\end{array}$ \\
\hline $\begin{array}{c}\text { Squamous } \\
\text { carcinoma }\end{array}$ & 27 & 25 & 5.4 \\
\hline Lymphoma & 27 & 25 & 5.4 \\
\hline $\begin{array}{c}\text { Basal cell } \\
\text { carcinoma }\end{array}$ & 9 & 8.3 & 1.8 \\
\hline Retinoblastoma & 16 & 14.8 & 3.2 \\
\hline Melanoma & 10 & 9.2 & 2 \\
\hline $\begin{array}{c}\text { Meibomian } \\
\text { carcinoma }\end{array}$ & 16 & 14.8 & 3.2 \\
\hline Other tumours & 3 & 2.7 & 0.6 \\
\hline \multicolumn{2}{|c|}{ Table 2. Malignant Tumours of the Orbit } \\
\hline
\end{tabular}

Source: Primary Data.

\begin{tabular}{|c|c|}
\hline Tumours & Number \\
\hline Neurofibroma & 9 \\
\hline Xanthomatous tumours & 4 \\
\hline Schwannoma & 3 \\
\hline Benign fibrous histiocytoma & 4 \\
\hline Fibroma & 4 \\
\hline Lipoma & 4 \\
\hline Haemangioendothelioma & 1 \\
\hline \multicolumn{2}{|c|}{ Table 3. Benign Connective Tissue Tumours } \\
\hline
\end{tabular}

Source: Primary Data.

Five hundred cases were included in the study. Among these, 392 were benign and 108 were malignant. Benign tumours mainly included nevus, squamous papilloma, angiomas, seborrhoeic keratosis and also cases of carcinoma in situ. Soft tissue tumours like neurofibroma, schwannoma, lipoma and fibrohistiocytic tumours were seen rarely. Tumours of skin, adnexa and lacrimal gland tumours also were seen rarely.

Malignant tumours were mainly squamous cell carcinoma, lymphoma, melanoma, meibomian carcinoma and basal cell carcinoma. Retinoblastoma was the commonest in paediatric age group. Rare tumours include salivary gland like tumours, such as adenoid cystic carcinoma and poorly differentiated carcinomas. Malignant soft tissue tumours and metastatic tumours were not received in the 7 yrs. period of study suggesting that they are very rare in occurrence in this part of the world.

These results were comparable to the studies conducted in Gujarat and Pakistan in the case of malignant tumours. In the study in Gujarat, squamous carcinoma is the commonest tumour. This is followed by meibomian carcinoma, melanoma and retinoblastoma. In the study conducted in Pakistan, squamous cell carcinoma, lymphoma and retinoblastoma shared the top of the chart.

In Netherlands, lymphoma was the commonest (67\%) among the malignant tumours. Malignant tumours of lacrimal gland constituted the commonest group in a Chinese study. Meibomian carcinoma was not mentioned in the studies from Netherlands, Pakistan and China, whereas it is quite common in Gujarat and Nepal. Basal cell carcinoma and Melanoma which are common among light skinned population were comparatively rare in the study.

Among the benign tumours, angiomas were the commonest in most of the studies, whereas nevus followed by squamous papilloma were the commonest in our study. Angiomas come third in incidence.

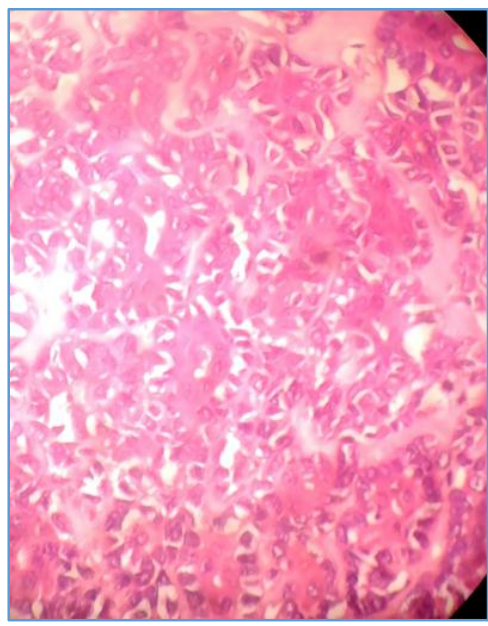

Figure 1. Chondroid Syringoma 


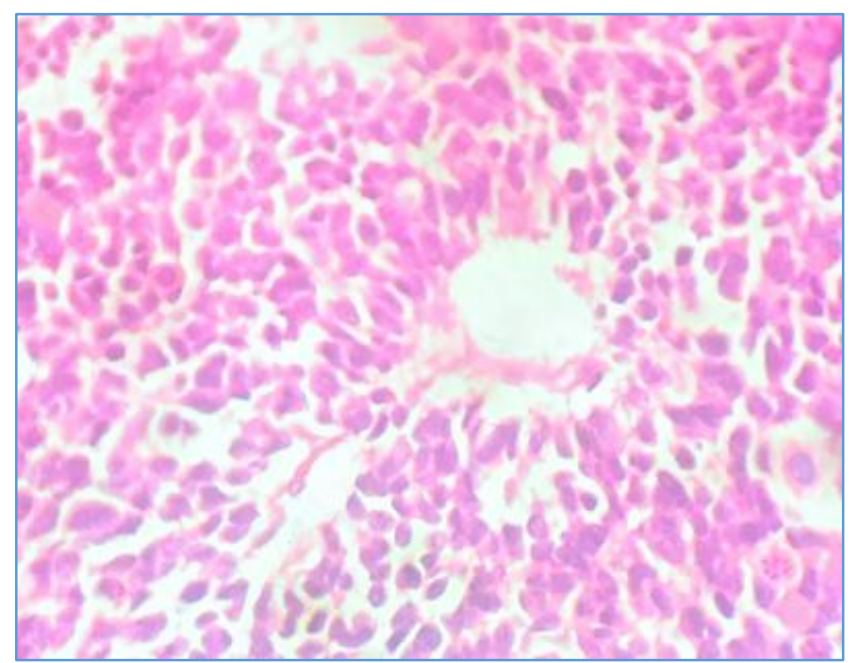

Figure 2. Retinoblastoma

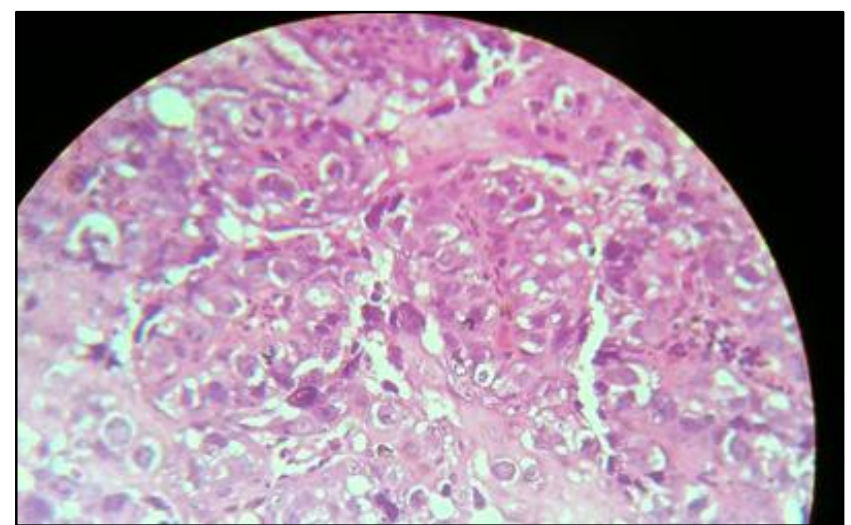

Figure 3. Meibomian Carcinoma

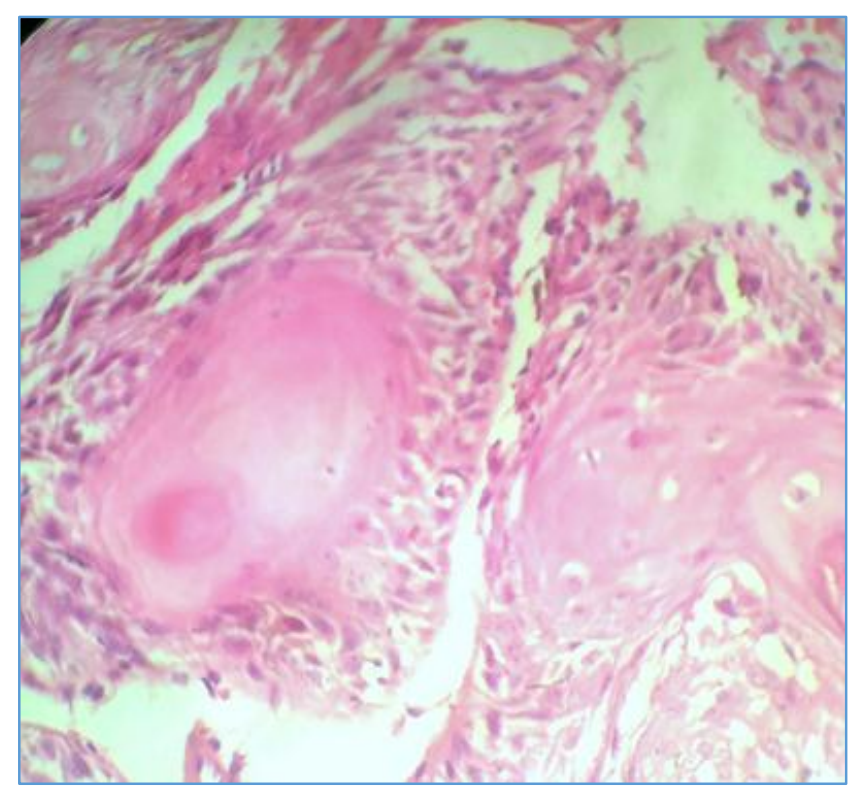

Figure 4. Squamous Carcinoma

\section{DISCUSSION}

From the results shown above, it is evident that the pattern of distribution of tumours in orbit differ in different regions of the world. Both benign and malignant neoplasms show this variation. In most of the studies, angiomas are the commonest benign tumour. However, in the current study, nevus and squamous papilloma are the commonest.
Nevus is the benign tumour of the pigment producing cells. It presents as a blackish raised or flat lesion. It may be mistaken for melanoma. The lack of dysplasia and invasion helps to differentiate it from melanoma. Features like sudden growth in size, colour change, loss of hair etc. suggest malignant transformation in these tumours. The incidence of nevi is higher in people with dark features. That might be the reason why it is commoner in India compared to the western countries.

Squamous papilloma, the second commonest benign tumour is arising from the lining squamous epithelium of skin. Grossly, it appears to be covered by dry wrinkled skin. Like the squamous papilloma elsewhere in the body, papilloma of eyelid is also caused due to the infection by Human Papilloma Virus or the Parvovirus. HPV strains of low risk causes benign tumours of squamous epithelium. The increased prevalence of viral infections or their poor management in Indian states might be the cause of high incidence of papilloma here.

The same can be said about the higher incidence of squamous intraepithelial neoplasia or Ocular Surface Squamous Neoplasia (OSSN), which is proven to be associated to infection by HPV. These lesions are actually squamous epithelial proliferations with varying degrees of atypia, even amounting to carcinoma in situ, but not invading into the underlying tissue.

Lacrimal glands are seats of tumours similar to those occurring in salivary glands, e.g. pleomorphic adenoma. Besides, the adnexa of the skin also give rise to appendage tumours like eccrine spiradenoma and chondroid syringoma. The incidence of chondroid syringoma is found to be more in the study when compared to the studies elsewhere. It is a tumour with a morphology very much similar to the Pleomorphic adenoma. It is composed of epithelial components like tubules, squamous islands and sebaceous glands and connective tissue components like chondroid, myxoid and fibroblastic elements (Fig. 1). The fact that the lacrimal gland tumours have close resemblance to the tumours of salivary gland proves that both these glands have similar origin, namely modified skin appendages. The reason behind the higher incidence of these tumours here is not clear.

Among the connective tissue tumours, angioma is very common and nerve sheath tumours are seen less frequent, while others like Lipoma, Xanthomatous tumours and Histiocytic tumours are still rare. The prevalence of Angioma in the study is comparable with other centres.

In the case of malignant tumours; however, the pattern in the study differs in many ways from the studies in non-Asian countries. Lymphoma is the commonest malignant primary tumour in most studies including the present study. While the cause of origin of lymphoma is not clear in most cases, viral infections are strongly suggested as possible aetiology. Infections by oncogenic viruses like Human papilloma virus, Epstein-Barr virus and Human Herpes virus are frequent. Intraocular lymphomas can be low grade like the MALT lymphomas or high grade like diffuse large B-cell lymphoma.

Among the children, Retinoblastoma is the commonest malignant tumour in all the studies conducted. It is a tumour composed of small round cells arranged in diffuse pattern along with formation of structures like Homer Wright rosette (Pseudorosettes), Flexner-Wintersteiner rosette (True 
rosettes) and Fleurettes (Fig. 2). However, the second commonest malignant tumour in children is Rhabdomyosarcoma that originates from skeletal muscle in studies conducted in Netherlands and China, whereas our study did not show even a single case. Since no specific risk factors are attached to this tumour, it is difficult to suggest a reason for the reduced incidence in our region.

Uveal melanoma is the commonest intraocular tumour in Europe and the US, while it is not that common in Asian countries. Metastatic adenocarcinomas and lacrimal gland tumours like the Adenoid cystic carcinoma are also common in Europe, but not frequently seen in India and China. While melanoma is a tumour with high incidence among white skinned people and its lower frequency in Asian countries can thus be explained. There is no clear explanation for the higher incidence of metastatic adenocarcinoma in Europe as compared to the Asian countries. The only suggestion that can be made is that the adenocarcinoma secondaries may be dominating the picture in Europe, because of the much lower incidence of Squamous cell carcinoma.

Meibomian carcinoma, on the contrary, is common in India and Nepal, (19\% and $9 \%$ of malignant tumours), while it is less than $3-4 \%$ elsewhere. It is a malignant tumour composed of cells arranged in lobules and sheets. The cells are large with sebaceous differentiation with central nuclei and vacuolated cytoplasm indicating cytoplasmic lipid. Large number of mitotic figures are seen (Fig. 3). The risk factors of this tumour include radiation exposure and Muir-Torre syndrome. When the exposure to the sun in tropical and temperate countries are definitely more, whether it carries more risk of exposure to UV rays is debatable, as the presence of the protective pigment melanin is more in the skin of the Asians.

Squamous cell carcinoma is the commonest tumour of the eye along with lymphoma in our study. This as already stated earlier can be attributed to the infection by high risk strains of HPV. Most cases were well differentiated carcinomas with the tumour cells showing differentiation towards the surface, individual cell keratinisation and the keratin pearls (Fig. 4).
Basal cell carcinoma on the other hand is one of the leading malignancies of the orbit in the studies abroad, while it comes only sixth in our study. However, it is known to be commoner among light skinned people, which must be the reason of higher incidence in Europe and Australia. The tumour, though malignant, shows less propensity to metastasize, hence called Rodent ulcer, only locally invasive.

\section{CONCLUSION}

The study shows that the prevalence of tumours of the orbit in Kerala are comparable to that in other Indian states and even to the studies from Pakistan and Nepal. This similarity can be attributed to the constitution, racial factors and the similarities in the lifestyle and other socioeconomic factors like having vaccinations, proper hygiene, dietary habits etc. However, the prevalence varies in studies from Europe and Australia, which might be due to racial factors and geographical factors like terrestrial radiation.

\section{REFERENCES}

[1] Koopman JH, van der Heiden-van der Loo M, van Dijk $\mathrm{MR}$, et al. Incidence of primary malignant orbital tumors in Netherlands. Eye (London) 2011;25(4):4615.

[2] Ni C, Ma X. Histopathologic classification of 1921 orbital tumors. Yan Ke Xue Bao 1995;11(2):101-4.

[3] Bastola P, Koirala S, Pokhrel G, et al. A clinicohistopathological study of orbital and ocular lesions a multicenter study. Journal of Chitwan Medical College 2013;3(4):40-4.

[4] Halepota FM, Talpur KI, Luhano MK, et al. Orbital tumors - retrospective study of 24 years. Pakistan Journal of Ophthalmology 2014;30(1):33-37.

[5] Sheikh IY, Shah FR, Gandhi MB, et al. Ophthalmic neoplastic lesions - a retrospective study of 4 years. Gujarat Medical Journal 2012;67(2):53-7. 